\title{
Comparison of samples found positive by anti-HCV screening test with line immunoassay and determination of threshold value
}

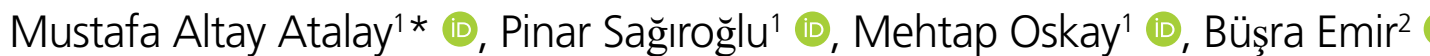

\begin{abstract}
SUMMARY
OBJECTIVE: This study aimed to compare the serum samples found reactive ( $\geq 1-\leq 20$ signal-to-cutoff ratio) with Elecsys antibodies to hepatitis $C$ virus screening test with innogenetics-line immunassay hepatitis $C$ Virus Score test and to determine the most appropriate threshold value for our country, since positive results close to the cutoff value cause serious problems in routine diagnostic laboratories. METHODS: Antibodies to hepatitis C virus-positive samples from 687 different patients were included in the study. Antibodies to hepatitis $C$ virus antibody detection was performed using Elecsys antibodies to hepatitis C virus II kits (Roche Diagnostics, Germany), an electrochemiluminescence method based on the double-antigen sandwich principle, on the Cobas e601 analyzer (Roche Diagnostics) in accordance with the recommendations of the manufacturer. Samples that were initially identified as reactive were studied again. Samples with $\geq 1-\leq 20$ signal-to-cutoff ratio reagents as a result of retest were included in the study to be validated with the third-Generation Line immunassay kit (innogenetics-line immunassay hepatitis C Virus, Belgium).

RESULTS: A total of 687 samples with antibodies to hepatitis C virus positive and levels between 1-20 S/Co were found to be $56.1 \%$ negative, $14.8 \%$ indeterminate, and $29.1 \%$ positive by innogenetics-line immunassay hepatitis $C$ Virus confirmation test. When the cases with indeterminate innogenetics-line immunassay hepatitis $C$ Virus test results were accepted as positive, the signal-to-cutoff ratio value for antibodies to hepatitis C virus was determined as 5.8 (95\% confidence interval) in distinguishing the innogenetics-line immunassay hepatitis $C$ Virus negative and positive groups.

CONCLUSION: It was concluded that with further studies on this subject, each country should determine the most appropriate S/Co value for its population, and thus it would be beneficial to reduce the problems such as test repetition and cost increase.

KEYWORDS: Hepatitis C virus antibodies. Enzyme immunoassay. Hepatitis C virus. Immunoassay.
\end{abstract}

\section{INTRODUCTION}

Early detection of hepatitis $\mathrm{C}$ virus (HCV) antibodies is the first step in the management of chronic hepatitis and identification of patients who are in need of treatment ${ }^{1,2}$. Firstgeneration anti-HCV tests were developed in 1990 using the recombinant c100-3 epitope of the NS4 protein and have limited sensitivity and specificity ${ }^{1,3}$. A second-generation assay was soon developed using a multi-antigen format, including epitopes from the core, NS3 and NS4 proteins $^{1,4}$. In the early 2000s, third-generation tests were introduced to detect the presence of antibodies against recombinant core, NS3, NS4, and NS5 antigens of the virus. The test format had also changed from an enzyme immunoassay (EIA) method to a chemiluminescent immunoassay (CLIA) method, with a marked improvement in performance ${ }^{1,5}$. The Elecsys antiHCV II test (Roche Diagnostics, Germany) works with the

${ }^{1}$ Erciyes University, School of Medicine, Department of Medical Microbiology - Kayseri, Turkey.

${ }^{2}$ Izmir Kâtip Celebi University, School of Medicine, Department of Biostatistics - Izmir, Turkey.

*Corresponding author: altayatalay@gmail.com

Conflicts of interest: the authors declare there are no conflicts of interest. Funding: none.

Received on August 16, 2021. Accepted on August 17, 2021. 
electrochemiluminescence (ECLIA) method and is based on the double-antigen sandwich principle ${ }^{5}$. The INNO-LIA HCV score test (Innogenetics, Belgium) is a line immunoassay (LIA) method recommended for use as an additional test for samples found reactive in the anti-HCV screening procedure. The INNO-LIA HCV Score assay uses well-defined antigens derived from $\mathrm{HCV}$ immunodominant proteins from the core, the E2 hypervariable region (HVR), the NS3 helix region, and the NS4A, NS4B, and NS5A regions ${ }^{6}$.

In societies with low prevalence of $\mathrm{HCV}$, such as our country, and in those with autoimmune disease, it has been reported that tests used to detect anti-HCV antibodies give high false-positive results ${ }^{7}$. Positive results close to the cutoff value cause serious problems in routine diagnostic laboratories (such as reporting problems, increased costs due to repeat testing or HCV-RNA testing). In contrast, the presence of HCV-RNA often does not accompany close to the cutoff value or low antiHCV positivity ${ }^{8}$. In this study, it was aimed to compare the samples with positive results $(\geq 1-\leq 20 \mathrm{~S} / \mathrm{Co})$ with the Elecsys anti-HCV screening test with the INNO-LIA Score test and to determine the threshold value for the anti-HCV screening test.

\section{METHODS}

A total of 687 anti-HCV-positive ( $\geq 1-\leq 20$ S/Co) serum samples from different patients sent to Erciyes University Medical Faculty Central Laboratory Serology Unit between January 2018 and April 2021 were included in the study. Then, the same sera were studied with the Third-Generation LIA kit (INNO-LIA, HCV Score, Innogenetics, Belgium). The results of both tests were evaluated retrospectively.

\section{Anti-HCV Antibody Detection}

Anti-HCV antibody detection was performed using Elecsys anti-HCV II kits (Roche Diagnostics), an ECLIA method based on the double-antigen sandwich principle, on the Cobas e601 analyzer (Roche Diagnostics) in accordance with the recommendations of the manufacturer. Samples with $<1 \mathrm{~S} / \mathrm{Co}$ value were considered nonreactive, while samples with $\geq 1 \mathrm{~S} /$ Co value were considered reactive. Samples that were initially identified as reactive were studied again. Samples with $\geq 1$ and $\leq 20 \mathrm{~S} / \mathrm{Co}$ reagents as a result of retest were included in the study to be validated with the Third-Generation LIA kit.

\section{Line Immunoassay}

Anti-HCV-positive samples were studied with the ThirdGeneration INNO-LIA HCV score test (Innogenetics, Belgium) kits containing the $\mathrm{C} 1, \mathrm{C} 2, \mathrm{E} 2$, NS3, NS4, and NS5 regions of the HCV genome in accordance with the recommendations of the manufacturer and were interpreted as negative, indeterminate, and positive.

Negative: All HCV antigen bands have a negative reactivity degree or one of the HCV antigen bands, except that NS3 has \pm reactivity.

Positive: Reactivity of \pm or higher in at least two HCV antigen bands.

Indeterminate: Any HCV antigen line has a reactivity rating of $1+$ or higher, or the NS3 band has reactivity of \pm or more, while all other antigen lines are negative.

\section{Statistical analysis}

Data were evaluated using statistical package program IBM SPSS Statistics for Windows, version 26.0 (IBM Corp. Released 2019, Armonk, NY, USA). In comparisons according to the INNOLIA HCV score verification test result categories, which had more than two subcategories, the Elecsys anti-HCV II screening test continuous measurement value distribution was evaluated by the Kruskal-Wallis test based on the normality test result. The Bonferroni test was used as a multiple comparison test. A $p<0.05$ value was considered statistically significant. In addition, the analysis of the data was performed with the MedCalc 15.8 program. As a result of the application of the INNO-LIA HCV score confirmation test, the Elecsys anti-HCV II screening test results of patients with anti-HCV positive; receiver operating charateristic (ROC) curve analysis was applied to determine the cutoff point as negative group with (indeterminate+positive) group and positive group with (negative+indeterminate) group.

\section{RESULTS}

A total of 687 samples were anti-HCV positive with results ranging from 1-20 S/Co, 385 (56.1\%) were negative with the INNO-LIA HCV score confirmatory test, 102 (14.8\%) were indeterminate, and 200 (29.1\%) was found positive. It was found that the distribution of anti-HCV-positive values by categories as a result of the INNO-LIA HCV score verification test did not provide the normal distribution assumption. The descriptive statistics and median value and the 25 th and 75 th percentile values of continuous measurement values that are anti-HCV positive and whose value varies between 1-20 S/Co according to each INNO-LIA HCV score test result categories are given in Table 1. The distribution of the measurement values of the anti-HCV-positive group according to the Kruskal-Wallis test result shows statistically significant differences according to the INNO-LIA HCV score result categories $(\mathrm{p}<0.001)$.

ROC curve analysis was used to determine the cutoff point of the negative group with (indeterminate+positive) group and the positive group with (indeterminate+negative) group as a result of 
application of the INNO-LIA HCV score confirmation test to the results found positive with the Roche Elecsys anti-HCV II test (Figures 1 and 2). As a result of the analysis, when the cases that were indeterminate according to the INNO-LIA HCV score test result were considered positive, the $\mathrm{S} / \mathrm{Co}$ value for anti-HCV was determined as 5.8 ( $95 \%$ confidence interval) in distinguishing the INNO-LIA HCV score test negative and positive groups. At S/ Co values $>5.8$, sensitivity was $79.1 \%$, specificity $78.2 \%$, positive predictive value $73.8 \%$, and negative predictive value $82.6 \%$. When the cases that were indeterminate according to the INNOLIA HCV score test result were considered negative, the $S / C o$ value for anti-HCV was determined as 7.3 (95\% confidence interval) for the INNO-LIA HCV score test in distinguishing the negative and positive groups. At $\mathrm{S} / \mathrm{Co}$ values $>7.3$, the sensitivity was $81 \%$, the specificity was $79.1 \%$, the positive predictive value was $61.1 \%$, and the negative predictive value was $91 \%$.

\section{DISCUSSION}

The diagnosis of HCV infection usually begins with the detection of anti-HCV using EIA and a CLIA screening methodss. Direct HCV-RNA testing is recommended in anti-HCV-positive patients with clinically acute or chronic liver disease due to the possibility of false-positive results in populations where prevalence is low $^{10}$. However, high costs, labor-intensive procedures, and the need for specialized equipment and qualified personnel limit the widespread use of molecular techniques ${ }^{9,11}$. Furthermore, deciding on a reliable, easy-to-use, and cost-effective test to predict true HCV infection status or $\mathrm{HCV}$ viremia in anti-HCV reactive patients remains controversial. Although it is recommended to confirm with tests such as Recombinant Immunoblot Assay (RIBA) when a low S/ Co result is obtained in the classical diagnosis algorithm of $\mathrm{HCV}$, these tests are likely to yield "indeterminate" results ${ }^{12}$. The Centers for Disease Control and Prevention (CDC) removed the RIBA test from the new algorithm and explained that the cutoff value of $\geq 1 \mathrm{~S} / \mathrm{Co}$ should be adjusted according to the characteristics of the population ${ }^{8}$. In addition, the $\mathrm{CDC}$ has proposed predictive cutoff values for some commercially available anti-HCV screening tests. For example, Architect (Abbott Laboratories, USA) has set a threshold value of $\geq 5 \mathrm{~S} / \mathrm{Co}$ for the anti-HCV screening test, but these values have not yet been specified for the Roche Elecsys antiHCV II tests ${ }^{9,13}$. Lai et al. ${ }^{14}$ reported that when the S/Co ratio is $<3.0$ or $\geq 20.0$, there is no need for anti-HCV confirmatory testing with RIBA because of the high true negative and high true positive rate, respectively. They also reported that the RIBA confirmatory test is required for patients with an S/Co ratio of 3.0-19.9, due to possible false-positive results given by the ECLIA. Results between 1.0 and 20 S/Co with the Elecsys anti-HCV II screening test in our laboratory are confirmed by the INNO-LIA HCV score test.

In our study, a total of 687 samples with reactive antiHCV results (1-20 S/Co) were tested with the INNO-LIA HCV score confirmation test. It was found that $56.1 \%$ were negative,

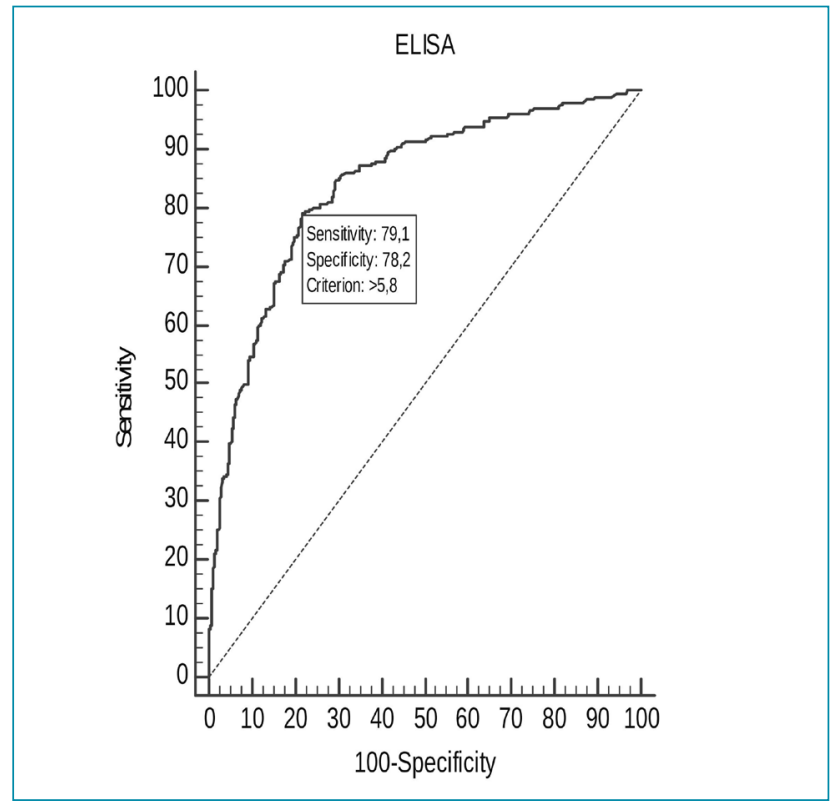

Figure 1. Receiver operating charateristic curve analysis of negative group with (indeterminate+positive) group.

Table 1. Evaluation of the distribution of Elecsys Antibodies to hepatitis C virus II screening test measurement values of patients with Antibodies to hepatitis C virus positive according to the confirmatory test Innogenetics- line immunassay hepatitis $C$ virus score test findings.

\begin{tabular}{|c|c|c|c|c|}
\hline INNO-LIA HCV score & $\mathrm{n}(\%)$ & $\begin{array}{c}\bar{X} \pm S S \\
M\left(Q_{1}-Q_{3}\right)\end{array}$ & p-value ${ }^{+}$ & Pairwise comparisons \\
\hline Negative & $385(56.0)$ & $\begin{array}{c}4.21 \pm 3.74 \\
2.66(1.54-5.40)\end{array}$ & \multirow{3}{*}{$\begin{array}{c}\chi^{2}=274.140 ; \\
p<0.001\end{array}$} & $1-2: p<0.001$ \\
\hline Positive & $200(29.2)$ & $\begin{array}{c}12.59 \pm 5.20 \\
12.86(8.36-16.83)\end{array}$ & & $1-3: p<0.001$ \\
\hline Indeterminate & $102(14.8)$ & $\begin{array}{c}7.29 \pm 4.56 \\
6.53(3.63-10.00)\end{array}$ & & $2-3: p<0.001$ \\
\hline
\end{tabular}

+Kruskal Wallis Test. INNO-LIA HCV score: Innogenetics-line immunassay hepatitis C virus 
$14.8 \%$ were indeterminate, and $29.1 \%$ were positive. It has been reported that a total of 47041 samples, which were found to be anti-HCV reactive by EIA method, was found to be positive in $49.3 \%$, indeterminate in $17.1 \%$, and negative in $33.5 \%$ by RIBA method ${ }^{15}$. In another study, two different anti-HCV systems (Cobas e411 Elecsys anti-HCV II and Vidas anti-HCV Biomerieux) were compared with the INNO-LIA HCV score test using 1931 serum samples. It has been reported that the performance agreement of Vidas and INNO-LIA for discrepant samples is 65\%, and the percentage agreement is $80 \%$ for Vidas-negative samples and 28\% for Vidas-positive samples. It was stated that Cobas had a performance agreement of $41 \%$ with INNO-LIA in discrepant samples, and the percentage agreement was $28 \%$ for Cobas negative samples and $72 \%$ for Cobas positive samples ${ }^{16}$. In a study where Architect i2000SR (Abbot Laboratories) and Vidas systems were used as anti-HCV screening test, 70 serum samples with low positive $(1 \leq \mathrm{S} / \mathrm{Co}<8)$ were compared with the INNO-LIA HCV score assay. It has been reported that the agreement between

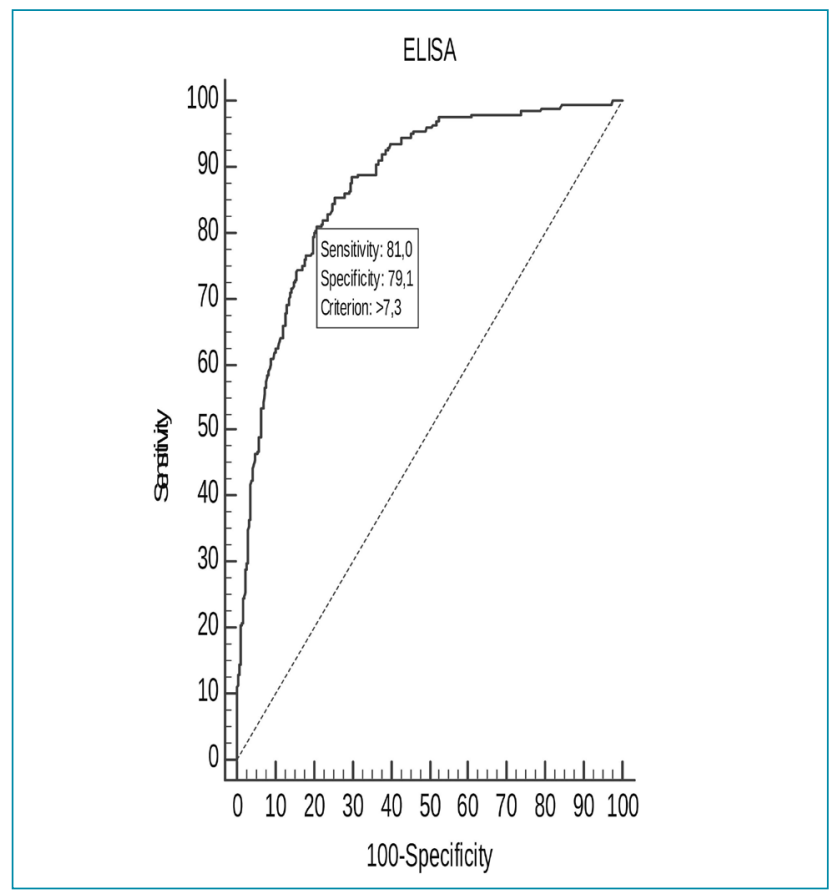

Figure 2. Receiver operating charateristic curve curve analysis of positive group with (indeterminate+negative) group. the Architect i2000SR and the INNO-LIA HCV score assay is 42.6\%, and the percentage agreement between Vidas and the INNO-LIA HCV score assay is $79.4 \%{ }^{17}$. A multicenter study conducted in Turkey reported that $67 \%$ of 10050 anti-HCVpositive serum samples were positive with RIBA ${ }^{18}$. In another study, this rate was found to be $61.4 \%{ }^{8}$. In our study, when the indeterminate results were considered positive, this rate was found to be $49.5 \%$.

Yang et al. ${ }^{1}$ reported that in the Elecsys anti-HCV II assay, an S/Co ratio of 20.0 predicted a true positive result $\geq 95 \%$ of the time. On the other hand, Wu et al. ${ }^{19}$ found that this value was 12.0 for the InTec test (InTec products, China) and 5.0 for the Architect test in their study in which they investigated the appropriate S/Co thresholds. Saribas et al. ${ }^{8}$ determined the S/Co value of 7.2 (95\% confidence interval) for Architect anti-HCV in distinguishing LIA positive and negative groups when LIA indeterminate cases were considered negative. In our study, when the results found indeterminate by the INNO-LIA HCV score assay were considered positive and negative, the $\mathrm{S} / \mathrm{Co}$ ratios for anti-HCV were found to be 5.8 and 7.3 , respectively.

\section{CONCLUSIONS}

The lack of HCV-RNA results in each patient limited us to make a comparison in this respect. Although the INNO-LIA $\mathrm{HCV}$ score assay is used as a complementary test in the detection of anti-HCV antibodies, it has the disadvantage of visual evaluation and highly uncertain results. As a result, it is necessary for each country to determine the most appropriate S/Co value for its population, with more studies to be done on this subject. This will reduce patient victimization due to reporting problems and problems such as increased cost due to repeated testing or the need for HCV-RNA testing.

\section{AUTHORS" CONTRIBUTIONS}

MAA: Conceptualization, Investigation, Writing - review \& editing. PS: Conceptualization, Data curation, Writing review \& editing. MO: Data curation, Writing - original draft, Writing - review \& editing. BE: Formal analysis.

\section{REFERENCES}

1. Yang R, Guan W, Wang Q, Liu Y, Wei L. Performance evaluation and comparison of the newly developed Elecsys anti-HCV II assay with other widely used assays. Clin Chim Acta. 2013;426:95-101. https://doi.org/10.1016/j.cca.2013.09.010
2. European Association for the Study of the Liver. Electronic address: easloffice@easloffice.eu. EASL recommendations on treatment of hepatitis C 2016. J Hepatol. 2017;66(1):153-94. https://doi.org/10.1016/j.jhep.2016.09.001 
3. Alter HJ, Purcell RH, Shih JW, Melpolder JC, Houghton $\mathrm{M}, \mathrm{Choo} \mathrm{QL}$, et al. Detection of antibody to hepatitis $C$ virus in prospectively followed transfusion recipients with acute and chronic non-A, non-B hepatitis. N Engl J Med. 1989;321(22):1494-500. https://doi.org/10.1056/ NEJM198911303212202

4. Van der Poel CL, Cuypers HT, Reesink HW, Weiner AJ, Quan S, Di Nello R, et al. Confirmation of hepatitis $C$ virus infection by new four-antigen recombinant immunoblot assay. Lancet. 1991;337(8737):317-9. https://doi.org/10.1016/01406736(91)90942-i

5. Alborino F, Burighel A, Tiller FW, van Helden J, Gabriel C, Raineri $A$, et al. Multicenter evaluation of a fully automated third-generation anti-HCV antibody screening test with excellent sensitivity and specificity. Med Microbiol Immunol. 2011;200(2):77-83. https://doi.org/10.1007/s00430-0100171-0

6. Carrasco T, Barquín D, Ndarabu A, Fernández-Alonso M, Rubio-Garrido M, Carlos S, et al. HCV diagnosis and sequencing using dried blood spots from patients in Kinshasa (DRC): a tool to achieve WHO 2030 targets. Diagnostics (Basel). 2021;11(3):522. https://doi.org/10.3390/ diagnostics11030522

7. Centers for Disease Control and Prevention. A guide to comprehensive hepatitis $C$ counseling and testing. Atlanta: CDC; 2019. [cited on Aug. 10, 2021]. Available from: https:// www.cmeoutfitters.com/wp-content/uploads/2019/12/Guideto-Comprehensive-Hep-C-Counseling-and-Testing.pdf

8. Saribas A, Aksoy A. Determination of Anti-HCV scanning test cut-off value by HCV-RNA and Line Immunoassay tests. Turk Hij Den Biyol Derg. 2020;77(3):319-24. https://doi.org/10.5505/ TurkHijyen.2020.67778

9. Sirin $M C$, Cicioglu Aridogan B, Sesli Cetin E, Sirin FB. Evaluation of biochemical, hematological, RIBA and PCR assays in predicting viremia in anti-HCV positive patients. J Infect Dev Ctries. 2019;13(8):736-43. https://doi.org/10.3855/ jidc. 11426

10. Contreras AM, Ochoa-Jiménez RJ, Celis A, Méndez C, Olivares L, Rebolledo CE, et al. High antibody level: an accurate serologic marker of viremia in asymptomatic people with hepatitis C infection. Transfusion. 2010;50(6):1335-43. https://doi. org/10.1111/j.1537-2995.2009.02571.x
11. Contreras AM, Tornero-Romo CM, Toribio JG, Celis A, Orozco-Hernández A, Rivera PK, et al. Very low hepatitis $C$ antibody levels predict false-positive results and avoid supplemental testing. Transfusion. 2008;48(12):2540-8 https://doi.org/10.1111/j.1537-2995.2008.01886.x

12. Tang W, Chen W, Amini A, Boeras D, Falconer J, Kelly $H$, et al. Diagnostic accuracy of tests to detect Hepatitis $C$ antibody: a metaanalysis and review of the literature. BMC Infect Dis. 2017;17(Suppl 1):695. https://doi.org/10.1186/s12879-017-2773-2

13. Zhang K, Wang L, Lin G, Li J. Is anti-hepatitis C virus antibody level an appropriate marker to preclude the need for supplemental testing. Intervirology. 2015;58(5):310-7. https://doi.org/10.1159/000441474

14. Lai KK, Jin M, Yuan S, Larson MF, Dominitz JA, Bankson DD Improved reflexive testing algorithm for hepatitis $C$ infection using signal-to-cutoff ratios of a hepatitis $C$ virus antibody assay. Clin Chem. 2011;57(7):1050-6. https://doi.org/10.1373/ clinchem.2010.158691

15. Kleinman SH, Stramer SL, Brodsky JP, Caglioti S, Busch MP. Integration of nucleic acid amplification test results into hepatitis $C$ virus supplemental serologic testing algorithms: implications for donor counseling and revision of existing algorithms. Transfusion. 2006;46(5):695-702. https://doi. org/10.1111/j.1537-2995.2006.00787.x

16. Gaballah AM, Esawy MM. Comparison of 2 different antibody assay methods, Elecsys Anti-HCVII (Roche) and Vidas Anti-HCV (Biomerieux), for the detection of antibody to hepatitis $C$ virus in Egypt. Diagn Microbiol Infect Dis. 2018;92(2):107-11. https://doi.org/10.1016/j.diagmicrobio.2018.05.013

17. Salvetti S, Lavinia F, Montenora I. Performance study of the automated immunoassay test anti-hepatitis $C$ virus Vidas for the qualitative detection of antibodies anti-hepatitis C virus. Microbiol Med. 2016;31(1):17-20. https://doi.org/10.4081/mm.2016.4808

18. Gurol E, Saban C, Oral O, Cigdem A, Armagan A. Trends in hepatitis $B$ and hepatitis $C$ virus among blood donors over 16 years in Turkey. Eur J Epidemiol. 2006;21(4):299-305. https:// doi.org/10.1007/s10654-006-0001-2

19. Wu S, Liu Y, Cheng L, Yin B, Peng J, Sun Z. Clinical evaluation of the signal-to-cutoff ratios of hepatitis $C$ virus antibody screening tests used in China. J Med Virol. 2011;83(11):1930-7. https://doi.org/10.1002/jmv.22168 